\title{
BMJ Open Regional differences in the care and outcomes of acute stroke patients in Australia: an observational study using evidence from the Australian Stroke Clinical Registry (AuSCR)
}

\author{
Mitchell Dwyer (D) , ${ }^{1}$ Karen Francis, ${ }^{2}$ Gregory M Peterson $(1),{ }^{3}$ Karen Ford, ${ }^{4}$ \\ Seana Gall, ${ }^{5}$ Hoang Phan (D) , ${ }^{5,6}$ Helen Castley, ${ }^{7}$ Lillian Wong, ${ }^{8}$ Richard White, ${ }^{9}$ \\ Fiona Ryan, ${ }^{10}$ Lauren Arthurson, ${ }^{11}$ Joosup Kim, ${ }^{12,13}$ Dominique A Cadilhac (D) , ${ }^{12,13}$ \\ Natasha A Lannin (D) ${ }^{14,15}$ on behalf of the AuSCR Consortium
}

To cite: Dwyer M, Francis K, Peterson GM, et al. Regional differences in the care and outcomes of acute stroke patients in Australia: an observational study using evidence from the Australian Stroke Clinical Registry (AuSCR). BMJ Open 2021;11:e040418. doi:10.1136/ bmjopen-2020-040418

- Prepublication history and supplemental material for this paper is available online. To view these files, please visit the journal online (http://dx.doi org/10.1136/bmjopen-2020040418).

DAC and NAL are joint senior authors.

Received 13 May 2020 Revised 30 November 2020 Accepted 07 December 2020

Check for updates

(C) Author(s) (or their employer(s)) 2021. Re-use permitted under CC BY-NC. No commercial re-use. See rights and permissions. Published by BMJ.

For numbered affiliations see end of article.

Correspondence to

Dr Natasha A Lannin;

Natasha.Lannin@monash.edu

\section{ABSTRACT}

Objective To compare the processes and outcomes of care in patients who had a stroke treated in urban versus rural hospitals in Australia.

Design Observational study using data from a multicentre national registry.

Setting Data from 50 acute care hospitals in Australia (25 urban, 25 rural) which participated in the Australian Stroke Clinical Registry during the period 2010-2015.

Participants Patients were divided into two groups (urban, rural) according to the Australian Standard Geographical Classification Remoteness Area classification. Data pertaining to 28115 patients who had a stroke were analysed, of whom 8159 (29\%) were admitted to hospitals located within rural areas.

Primary and secondary outcome measures Regional differences in processes of care (admission to a stroke unit, thrombolysis for ischaemic stroke, discharge on antihypertensive medication and provision of a care plan), and survival analyses up to 180 days and health-related quality of life at $90-180$ days.

Results Compared with those admitted to urban hospitals patients in rural hospitals less often received thrombolysis (urban $12.7 \%$ vs rural $7.5 \%, p<0.001$ ) or received treatment in stroke units (urban $82.2 \%$ vs rural $76.5 \%$, $\mathrm{p}<0.001$ ), and fewer were discharged with a care plan (urban $61.3 \%$ vs rural $44.7 \%, p<0.001$ ). No significant differences were found in terms of survival or overall selfreported quality of life.

Conclusions Rural access to recommended components of acute stroke care was comparatively poorer; however, this did not appear to impact health outcomes at approximately 6 months.

\section{INTRODUCTION}

Internationally, evidence suggests that patients who had a stroke admitted to hospitals located in rural or regional areas have limited access to known evidence-based interventions, such as thrombolysis and stroke unit
Strengths and limitations of this study

- This is the first study in Australia to look at how access to acute stroke care varies between Australia's urban and rural areas, using data from the Australian Stroke Clinical Registry (AuSCR).

- This study also reports on regional differences in patient outcomes in the form of mortality and healthrelated quality of life at up to 180 days poststroke.

- Patient outcome measures were adjusted for known confounders.

- Hospitals participating in the AuSCR may not be representative of all Australian hospitals.

care, relative to those treated in urban hospitals. ${ }^{1}$ There is a paucity of research investigating disparities in other, more elementary processes which define contemporary standards of acute stroke care, such as the prescription of secondary prevention medications. In addition, if there are differences in stroke care between urban and rural regions, determining if there are corresponding differences in patient outcomes warrants attention so as to permit future exploration of organisational, process or patient barriers preventing evidence-based stroke care being received.

Overall, prior research on the rural and urban outcomes of care has yielded inconsistent findings, ${ }^{1}$ and is characterised by studies with inadequate risk adjustment ${ }^{2-4}$ or an indirect focus on urban-rural differences in outcomes. ${ }^{5-7}$ Previous attempts to explore this issue have also been reliant on 'hard' outcome measures such as rates of mortality and readmission, ${ }^{8-10}$ whereas regional differences in patients' quality of life have been 
rarely investigated. ${ }^{11}{ }^{12}$ Given this knowledge gap, the aim of this study was to compare the processes of care and outcomes for patients who had a stroke treated in urban compared with rural hospitals.

\section{METHODS}

\section{Study design}

We undertook a multicentre observational cohort study of adults admitted to hospital who had acute stroke using linked data from the Australian Stroke Clinical Registry (AuSCR) (see protocol ${ }^{13}$ and www.auscr.com.au). The AuSCR is used to monitor processes of care provided to, and the outcomes of, individuals hospitalised with acute stroke or transient ischaemic attacks (TIAs) in Australian hospitals primarily for quality improvement and benchmarking activities. ${ }^{13}$ Cases are entered prospectively in the AuSCR based on clinical diagnosis of stroke during admission. Case ascertainment is checked annually using International Classification of Diseases-10 discharge codes obtained from the hospital administrative system and compared with the cases entered in the registry at each hospital. A complete list of coinvestigators and other contributors to the AuSCR is found in online supplemental file 1. Death information (date and cause) from Australia's National Death Index is routinely linked to the AuSCR by the Australian Institute of Health and Welfare. ${ }^{14}$ For this study, we used data from all 50 hospitals that submitted data to the AuSCR from January 2010 to December 2015. Patients diagnosed with TIAs were excluded from the analyses as these individuals are unlikely to require the care processes of interest in this study. As of 2015, the 50 hospitals covered by the AuSCR accounted for approximately $46 \%$ of all Australian hospitals receiving $\geq 50$ stroke admissions per annum. ${ }^{15}$ Selection bias is minimised in the AuSCR by use of an 'opt-out' approach when recruiting participants, whereby all eligible patients are registered unless they or their next of kin nominates to have their data excluded. ${ }^{13}$ The proportion of cases who opt out from the registry is $<3 \%$ in urban and rural hospitals. Patients who did not opt out of the registry and who were discharged from hospital following their stroke were followed up by trained research staff between 90 and 180 days after their index admission (ie, the first registered event in AuSCR). This process uses a modified Dillman protocol, ${ }^{16}$ whereby two attempts are made to contact patients by post prior to an attempt by telephone. $^{17}$

Process of care data collected in AuSCR up to 2015 were admission to a stroke unit, thrombolysis (ischaemic stroke only), discharge on antihypertensive medication and provision of a care plan. Care plans are developed with the patient and family if discharged from acute care directly to the community (ie, to a home setting or institutional residential aged care and not transferred to another hospital, ie, for rehabilitation). This is not the discharge summary written by hospital clinicians for the primary care doctor; the discharge care plan should include information to improve the transition to home, such as arrangements for community support services, information on risk factor management, equipment to be purchased and follow-up appointments. Hospitals located in the state of Queensland also collected four additional variables: time to first mobilisation, dysphagia screen, aspirin within 48 hours and being discharged on antiplatelets or antithrombotics in case of an ischaemic event. Indicator data with responses of no, unknown or missing were recoded as negative (the proportion of missing data ranged from $<1 \%$ to $5.05 \%$ ). Regional differences in patient mortality were assessed using intervals of 7, 30, 90 and 180 days.

Participants' health-related quality of life (HRQoL) data were collected at 90-180 days of follow-up using the EuroQoL-5 Dimension-3 Level (EQ-5D-3L) instrument. ${ }^{18}$ Respondents were asked to report their health status in five domains (mobility, self-care, usual activities, pain or discomfort, and anxiety or depression), with each domain having three possible responses (no problems, some problems and extreme problems). Respondents used a Visual Analogue Scale (VAS) to rate their overall perceived health from 0 to 100 , with 0 being the worst imaginable health state and 100 the best imaginable health state ${ }^{18}$ The VAS was coded as 0 for individuals who had died within the follow-up period.

\section{Statistical analysis}

The primary exposure variable of interest was classification of hospital (urban vs rural), and the primary outcomes were survival analyses up to 180 days and HRQoL as assessed on the EQ-5D-3L. Hospitals were divided into categories of 'urban' or 'rural' based on their classification under the Australian Standard Geographical Classification Remoteness Area (ASGC-RA) system. ${ }^{19}$ The ASGC-RA system classifies areas into five categories: major cities, inner regional, outer regional, remote or very remote. ${ }^{19}$ For the purpose of this study, hospitals located in ASGC-RA category 1 (ie, major cities) were regarded as 'urban', while those in categories 2 or above were regarded as 'rural'. Interactive maps with overlays of the remoteness area categories can be accessed via the Australian Bureau of Statistics website. ${ }^{20}$ The majority of hospitals ( $>95 \%)$ that contribute data to AuSCR are funded under the public healthcare scheme. Participants' baseline characteristics were compared between regions using $\chi^{2}$ tests for categorical data and Wilcoxon rank-sum tests for continuous variables. Care processes were expressed as the proportion of eligible patients who received each form of care and were analysed by location (urban or rural) using $\chi^{2}$ tests. Participants' responses to the EQ-5D-3L instrument were expressed as the number of individuals who encountered problems with each domain, with 'some problems' and 'extreme problems' being recoded into one category. Regional differences within each domain were then analysed using $\chi^{2}$ tests.

Cox proportional hazards regression analysis was conducted to assess deaths within 7, 30, 90 and 180 days. 
Logistic regression was used to assess regional differences in each of the EQ-5D-3L domains. Models were adjusted for age, sex, year of admission, state, type of stroke, ability to walk on admission (as a validated measure of stroke severity) $^{21}$ and socioeconomic status (SES) using the Index of Relative Socio-economic Advantage and Disadvantage. $^{22}$ Each regression model also accounted for interhospital transfers, in-hospital stroke and whether the individual received treatment in a stroke unit. Patient clustering was adjusted for directly in each of our models to account for correlation between patients admitted to the same hospital. A sensitivity analysis was undertaken using data sets where interhospital transfers were excluded to assess the potential impact of this variable on patient outcomes. Data were analysed using Stata/SE V.12. ${ }^{23}$

\section{Patient and public involvement}

Patients and/or the public were not directly involved in the design, recruitment or implementation of the study. Consumer representatives are members of the AuSCR Steering Committee, and regular reviews by consumers of the AuSCR documents (policies and reports) are undertaken.

\section{RESULTS}

Between 2010 and 2015, 28115 episodes of care from 50 hospitals were registered in the AuSCR. Of these episodes, 8159 (29\%) were for individuals admitted to hospitals located within rural areas. Compared with those from urban areas, individuals from rural areas were more likely to have been born in Australia, have an indigenous background and be of a lower SES (table 1). Rural patients were also more likely than urban patients to be diagnosed with a stroke of 'undetermined' subtype $(8.1 \%$ vs $3.6 \%)$. When compared with urban patients, those treated in rural hospitals had poorer access to several clinical processes of care (table 2; online supplemental file 2 for variables collected only in Queensland). Specifically, rural patients were less likely to be admitted to a stroke unit $(\mathrm{OR}=0.70,95 \% \mathrm{CI} 0.66$ to 0.74$)$, receive intravenous thrombolysis in ischaemic stroke ( $\mathrm{OR}=0.55,95 \% \mathrm{CI} 0.50$ to 0.62 ) or be provided with a care plan at time of discharge $(\mathrm{OR}=0.59,95 \% \mathrm{CI} 0.54$ to 0.64$)$. There were no significant differences between regions in the prescribing rates of antihypertensive medications at discharge (OR $=0.97$, $95 \%$ CI 0.91 to 1.03 ). Regional differences in the proportion of patients discharged home were not observed, but urban patients were more likely to die in hospital in the unadjusted comparisons (table 2). The median length of stay for rural patients was 1 day shorter than that of urban patients, and this remained the case after adjustment for potential confounders (coefficient $-1,95 \%$ CI -1.97 to $-0.03)$.

There were no significant differences between geographical groups in terms of survival up to 180 days (table 3). In relation to HRQoL, no regional differences were observed in four of the EQ-5D domains, namely anxiety/depression, mobility, self-care and usual activities (table 4). Rural patients were, however, significantly less likely to have reported symptoms of pain or discomfort during the follow-up period ( $\mathrm{OR}=0.88,95 \%$ CI 0.79 to $0.97, \mathrm{p}=0.015)$. Rural patients also had marginally higher perceived health, as measured by VAS, than their urban counterparts ( 70 vs $68, \mathrm{p}<0.001)$. The sensitivity analysis that excluded transferred patients did not influence the results.

\section{DISCUSSION}

The primary aim of this study was to assess whether there are differences in the quality of care and outcomes for patients treated in urban and rural locations. We found that patients admitted to rural hospitals in Australia were less likely to receive some key care processes that are recommended in our national stroke clinical guidelines. ${ }^{24}$ However, for the most part, we did not observe corresponding differences in patient outcomes at 90-180 days.

Patients admitted to rural hospitals were significantly less likely to receive treatment in a stroke unit $(76.5 \%$ vs $82.2 \%$ ) despite only one rural hospital not being equipped with a stroke unit $(\mathrm{n}=30$ episodes of care). This finding suggests that while nearly all rural sites had facilities which met the minimum criteria for stroke units, ${ }^{25}$ many were unable to use their stroke unit's full potential. As observed by Dwyer, ${ }^{26}$ hospitals without 'quarantined' stroke unit beds may be unable to offer specialist care to patients who had a stroke at times when there is demand for beds from other medical specialties. Such hospitals may benefit from using clinical coordinators to facilitate organisational change, as recommended by Cadilhac and colleagues. $^{27}$

It should be noted that during the study period only $45 \%$ of patients located in Australia's 'regional' areas received treatment in a stroke unit and only $3.3 \%$ of all stroke unit beds were located in regional areas. ${ }^{28}{ }^{29}$ Taken together, these statistics indicate that access to stroke units within rural hospitals participating in the AuSCR was markedly better than the national average. Given that there is a well-established link between stroke unit admission and access to key aspects of acute stroke care, ${ }^{30}$ future efforts should focus on increasing the number of stroke units within Australia's regional areas and improving access to existing stroke units. Adherence rates in the current study were, for the most part, representative of that of more recent stroke care audits in Australia. ${ }^{31} 32$ The main exception was in rates of care plan provision; on average $53 \%$ of patients in the current study received this form of care, which was substantially lower than that of AuSCR data from $2018(69 \%)^{32}$ and data from the Stroke Foundation's 2019 Acute Audit $(65 \%))^{31}$

Consistent with other studies, rural patients remained less likely than urban patients to be administered thrombolysis. The provision of thrombolysis is known to be influenced by a host of patient, clinician and systemrelated factors. ${ }^{33}$ Of these factors, patients' distance 
Table 1 Patient characteristics by region

\begin{tabular}{|c|c|c|c|}
\hline Characteristics & Urban, n (\%) & Rural, n (\%) & $P$ value \\
\hline Number of sites & $25(50)$ & $25(50)$ & \\
\hline Number of cases & $19956(71)$ & $8159(29)$ & \\
\hline Female & $9095(45.6)$ & 3770 (46.2) & 0.335 \\
\hline \multicolumn{4}{|l|}{ Age (years) } \\
\hline$<65$ & $4910(24.6)$ & $2095(25.7)$ & 0.030 \\
\hline $65-74$ & $4468(22.4)$ & $1887(23.1)$ & \\
\hline $75-84$ & $6141(30.8)$ & 2469 (30.3) & \\
\hline $85+$ & 4431 (22.2) & 1707 (20.9) & \\
\hline Median age in years $(\mathrm{Q} 1, \mathrm{Q} 3)^{\star}$ & $76.1(65.2,84.2)$ & $75.4(64.7,83.6)$ & 0.003 \\
\hline \multicolumn{4}{|l|}{ State } \\
\hline New South Wales & $3252(16.3)$ & $805(9.9)$ & $<0.001$ \\
\hline Queensland & $6675(33.4)$ & $4401(53.9)$ & \\
\hline Tasmania & - & $1118(13.7)$ & \\
\hline Victoria & $9133(45.8)$ & $1835(22.5)$ & \\
\hline Western Australia & $896(4.5)$ & - & \\
\hline Born in Australia & $11916(59.7)$ & $6282(77)$ & $<0.001$ \\
\hline Aboriginal/Torres Strait Islander & $174(0.9)$ & $262(3.2)$ & $<0.001$ \\
\hline \multicolumn{4}{|c|}{ Index of Relative Socio-Economic Advantage and Disadvantage } \\
\hline Quintile 1 (most disadvantaged) & 2367 (12.3) & $2557(34.4)$ & $<0.001$ \\
\hline Quintile 2 & $2764(14.3)$ & $1932(26)$ & \\
\hline Quintile 3 & 3335 (17.3) & $1603(21.6)$ & \\
\hline Quintile 4 & $4837(25.1)$ & $1092(14.7)$ & \\
\hline Quintile 5 (most advantaged) & $5986(31)$ & $244(3.3)$ & \\
\hline Able to walk on admission (stroke severity) & $6055(32.7)$ & $2439(34.6)$ & 0.003 \\
\hline \multicolumn{4}{|l|}{ Stroke subtype } \\
\hline Intracerebral haemorrhagic & $3247(16.3)$ & $1177(14.4)$ & $<0.001$ \\
\hline Ischaemic & $15962(80.1)$ & $6313(77.5)$ & \\
\hline Undetermined & $709(3.6)$ & $658(8.1)$ & \\
\hline Transfer from other hospitals & $2191(11.2)$ & $1739(21.6)$ & $<0.001$ \\
\hline In-hospital stroke & $1156(5.9)$ & $407(5.1)$ & 0.008 \\
\hline Length of stay, median $(\mathrm{Q} 1, \mathrm{Q} 3)^{\star}$ days & $6(3,10)$ & $5(2,8)$ & $<0.001$ \\
\hline Died in hospital† & $2216(11.3)$ & $720(9.5)$ & $<0.001$ \\
\hline \multicolumn{4}{|l|}{ Discharge destination } \\
\hline Home & $7353(41.4)$ & $2899(39)$ & 0.092 \\
\hline Rehabilitation & $6234(35.1)$ & $2137(28.7)$ & $<0.001$ \\
\hline Aged care & $1057(6)$ & $326(4.4)$ & $<0.001$ \\
\hline Other & $3096(17.5)$ & 2077 (27.9) & $<0.001$ \\
\hline \multicolumn{4}{|l|}{ EQ-5D domains } \\
\hline \multicolumn{4}{|l|}{ Mobility } \\
\hline No problems & $4171(47.1)$ & $1791(48.4)$ & \\
\hline Some problems & $4056(45.8)$ & $1714(46.4)$ & \\
\hline Extreme problems & $631(7.1)$ & $193(5.2)$ & $<0.001$ \\
\hline \multicolumn{4}{|l|}{ Self-care } \\
\hline No problems & $5784(65.2)$ & $2499(67.4)$ & \\
\hline Some problems & $2012(22.7)$ & $872(23.5)$ & \\
\hline
\end{tabular}




\begin{tabular}{lccc}
\hline Table 1 Continued & & & \\
\hline Characteristics & Urban, $\mathbf{n}(\%)$ & Rural, $\mathbf{n}(\%)$ & P value \\
\hline$\quad$ Extreme problems & $1069(12.1)$ & $339(9.1)$ & $<0.001$ \\
Usual activities & & & \\
$\quad$ No problems & $3445(38.9)$ & $1448(39.1)$ & \\
$\quad$ Some problems & $3590(40.6)$ & $1571(42.3)$ & \\
$\quad$ Extreme problems & $1809(20.5)$ & $688(18.6)$ & 0.034 \\
Pain/discomfort & & & \\
$\quad$ No problems & $4401(50)$ & $1876(50.9)$ & \\
Some problems & $3955(44.9)$ & $1622(44)$ & 0.621 \\
$\quad$ Extreme problems & $446(5.1)$ & $190(5.1)$ & \\
Anxiety/depression & & & \\
$\quad$ No problems & $4632(52.8)$ & $1948(52.9)$ & \\
$\quad$ Some problems & $3630(41.3)$ & $1527(41.5)$ & \\
Extreme problems & $518(5.9)$ & $208(5.6)$ & \\
\hline
\end{tabular}

${ }^{*} \mathrm{Q} 1:$ 25th percentile; Q3: 75th percentile.

$\dagger<5 \%$ missing/not documented data.

EQ-5D, EuroQoL-5 Dimension.

to hospitals, accessing brain imaging after-hours and obtaining specialist input are among the most pertinent issues encountered by clinicians providing thrombolysis in rural areas. ${ }^{34-36}$ Rural-based clinicians in the Australian state of Victoria have been able to obtain specialist input and improve thrombolysis rates through the use of a telemedicine programme. ${ }^{37}$ Such a system was implemented in the state of Victoria for a small part of the study period, ${ }^{37}$ and as such may have influenced adherence rates in this group of hospitals. The use of telemedicine technology in all regional areas of the country is urgently needed in order to increase rates of thrombolysis administration. ${ }^{38}$

We did not observe differences by location in rates of prescription for antihypertensive medications at hospital discharge. As has been noted previously, ${ }^{39}$ this may reflect the fact that the management of patients' blood pressure for primary or secondary prevention is not necessarily specific to stroke and does not require any additional resources. In any case, the rates

\begin{tabular}{|c|c|c|c|}
\hline & Urban, $\mathbf{n}(\%)$ & Rural, n (\%) & $P$ value \\
\hline \multicolumn{4}{|c|}{ Evidence-based therapies (all states) } \\
\hline $\begin{array}{l}\text { Treated in a stroke } \\
\text { unit }\end{array}$ & $16408(82.2)$ & $6241(76.5)$ & $<0.001$ \\
\hline $\begin{array}{l}\text { Intravenous } \\
\text { thrombolysis for } \\
\text { ischaemic stroke }\end{array}$ & $2007(12.7)$ & $463(7.5)$ & $<0.001$ \\
\hline $\begin{array}{l}\text { Discharged on } \\
\text { antihypertensives }\end{array}$ & $12184(70.6)$ & 4895 (69.9) & 0.315 \\
\hline $\begin{array}{l}\text { Care plan on } \\
\text { discharge to } \\
\text { community }\end{array}$ & $4871(61.3)$ & $1441(44.7)$ & $<0.001$ \\
\hline
\end{tabular}

of prescription for antihypertensive medications at discharge from both regions were substantially less than expected based on previous AuSCR data, indicating that more work needs to be done to improve this aspect of evidence-based care. ${ }^{40}$

Despite marked differences in access to stroke unit care and thrombolysis, we did not observe any regional differences in rates of survival at up to 180 days poststroke. This may be because access to acute stroke care, when considered in its entirety, was reasonably comparable between the study's urban and rural hospitals. This notion is supported by the fact that the study's rural hospitals, by virtue of their participation in the registry, are likely to be highly motivated to monitor and improve their provision of stroke care and perhaps are better resourced than other rural sites. Furthermore, there is evidence that within the state of Queensland (online supplemental file 2) patients in rural hospitals were provided evidence-based therapies

Table 3 Survival analysis of rural patients who had a stroke as compared with urban patients

\begin{tabular}{|c|c|c|c|c|c|}
\hline \multirow{2}{*}{$\begin{array}{l}\text { Time to } \\
\text { death }\end{array}$} & \multirow{2}{*}{$\begin{array}{l}\text { Urban } \\
\mathrm{n}(\%) \\
\end{array}$} & \multirow{2}{*}{$\begin{array}{l}\text { Rural } \\
\mathrm{n}(\%)\end{array}$} & \multirow{2}{*}{$\begin{array}{l}P \\
\text { value }\end{array}$} & \multicolumn{2}{|c|}{ Model* } \\
\hline & & & & HR & $95 \% \mathrm{Cl}$ \\
\hline Up to 7 days & 1750 (8.8) & 769 (9.4) & 0.081 & 0.98 & 0.79 to 1.21 \\
\hline 8-30 days & 1242 (6.2) & $491(6)$ & 0.608 & 1.02 & 0.87 to 1.20 \\
\hline $31-90$ days & $745(3.7)$ & 265 (3.2) & 0.055 & 0.88 & 0.73 to 1.06 \\
\hline $\begin{array}{l}91-180 \\
\text { days }\end{array}$ & $526(2.6)$ & $202(2.5)$ & 0.439 & 0.88 & 0.69 to 1.11 \\
\hline
\end{tabular}

*Models were adjusted for age, sex, year of admission, state, type of stroke, ability to walk on admission, socioeconomic status, interhospital transfers, in-hospital stroke and stroke unit admission. 
Table 4 Outcomes at 90-180 days of follow-up of rural patients as compared with urban patients

\begin{tabular}{|c|c|c|c|c|c|c|}
\hline \multirow[b]{2}{*}{ EQ-5D domains } & \multirow[b]{2}{*}{ Urban, n (\%) } & \multirow[b]{2}{*}{ Rural, n (\%) } & \multirow[b]{2}{*}{$P$ value } & \multicolumn{3}{|c|}{ Model* } \\
\hline & & & & OR & $95 \% \mathrm{Cl}$ & P value \\
\hline Mobility & 4687 (52.9) & 1907 (51.6) & 0.169 & 1.02 & 0.92 to 1.13 & 0.717 \\
\hline Usual activities & $5399(61)$ & 2259 (60.9) & 0.910 & 0.95 & 0.85 to 1.06 & 0.376 \\
\hline Pain/discomfort & $4401(50)$ & $1812(49.1)$ & 0.376 & 0.88 & 0.79 to 0.97 & 0.015 \\
\hline $\begin{array}{l}\text { Median Visual Analogue Scale } \\
\text { score (Q1, Q3) }\end{array}$ & $68(40,80)$ & $70(50,83)$ & $<0.001$ & - & - & - \\
\hline
\end{tabular}

*Models were adjusted for age, sex, year of admission, state, type of stroke, ability to walk on admission, socioeconomic status, interhospital transfers, in-hospital stroke and stroke unit admission. EQ-5D, EuroQoL-5 Dimension.

more often than those in urban hospitals. These differences warrant further research.

In relation to HRQoL, we observed that with the exception of the pain/discomfort domain, there were no significant regional differences in any of the EQ-5D domains or VAS scores. These findings stand in contrast to multiple surveys conducted by the Australian government in which rural residents had an overall lower self-reported health status. ${ }^{4142}$ The disparity between regions in terms of selfreported pain/discomfort may point towards regional differences in attitudes towards pain management. Indeed, literature on patients with cancer in Australia has highlighted that a culture of stoicism and self-reliance within rural areas can make individuals less likely to report symptoms of pain $^{43}$ and delay seeking medical assistance. ${ }^{44}$ There are other demographic factors which may partially explain this finding. For instance, previous researchers using the AuSCR data have found that patients who had a stroke requiring an interpreter are more likely to report symptoms of pain. ${ }^{45}$ Given that urban patients in this study were far less likely to have been born in Australia (ie, $59.7 \%$ vs $77 \%$ ), the impact of the respondents' English-speaking ability on our findings cannot be discounted. Previous research using the AuSCR data has also highlighted that, other factors remaining equal, younger people from a lower SES are more likely to report symptoms of anxiety/depression. ${ }^{46}$ We also found that rural patients had a significantly higher perceived health status than urban patients ( 70 vs 68 via VAS); however, it is unlikely that this difference represents a clinically relevant finding. ${ }^{47}$

Our study design and data have several limitations. First, we report data only up to 2015 . As with clinical quality registries internationally, ${ }^{48}$ there is a delay in creating aggregate national samples from local sites due to data sharing, ethics and cleaning delays. Ongoing reporting of the AuSCR data to continue to monitor quality of care and outcomes for patients treated in urban and rural locations will ensure continued monitoring of this issue. Specific to this comparison, we acknowledge that the distribution of urban and rural patients in this study
(71\% vs $29 \%$ ) may not reflect that of the broader Australian hospital population, which recently stood at $64 \%$ and $36 \%$, respectively. ${ }^{49}$ We also did not use any data in relation to participants' residential addresses. It is therefore possible that some individuals who were admitted to urban hospitals resided in rural areas and vice versa. A further limitation is that our HRQoL data did not factor in patients' health prior to their stroke, meaning it is possible that some individuals' HRQoL deficits may relate to pre-existing conditions. Lastly, although we used patients' baseline walking ability as a validated measure of stroke severity, ${ }^{21}$ the study may have benefited from the use of a more recognised scale, such as the National Institutes of Health Stroke Scale. Despite these limitations, our study is the first of its kind in Australia to comprehensively examine urban-rural differences in access to acute stroke care and the associated patient outcomes. To the best of the authors' knowledge, it is also among the first in the world to report on urban-rural differences in patients' quality of life poststroke.

\section{CONCLUSIONS}

This is the largest study to date examining geographical disparities in processes of stroke care and providing a benchmark for the development and testing of interventions that may have the potential to reduce the differences between rural and urban patients who had acute stroke. Interestingly, while we identified disparities in processes of care, we did not observe any association between geographical region and patient outcomes in terms of mortality or HRQoL. There are clear opportunities to better understand why the impact of these process of care variables on stroke outcomes are more pronounced in urban areas. Our findings underscore the importance of understanding how geographical area influences HRQoL and in turn how population disparities (such as life expectancy, income and indigenous status) across geographical areas may contribute to these differences; continued efforts to determine the impact of stroke care postdischarge are important. Future work in 
this field should also focus on redressing the resourcing disparities, in particular increasing the number of rural hospitals which meet the minimum criteria for stroke unit care.

\section{Author affiliations}

${ }^{1}$ Tasmanian School of Medicine, College of Health and Medicine, University of

Tasmania, Hobart, Tasmania, Australia

${ }^{2}$ School of Nursing, College of Health and Medicine, University of Tasmania, Launceston, Tasmania, Australia

${ }^{3}$ School of Pharmacy and Pharmacology, College of Health and Medicine, University of Tasmania, Hobart, Tasmania, Australia

${ }^{4}$ Centre of Education and Research Nursing and Midwifery, Royal Hobart Hospital, Hobart, Tasmania, Australia

${ }^{5}$ Menzies Institute for Medical Research, University of Tasmania, Hobart, Tasmania, Australia

${ }^{6}$ Department of Public Health Management, Pham Ngoc Thach University of Medicine, Ho Chi Minh City, Viet Nam

${ }^{7}$ Neurology Department, Royal Hobart Hospital, Hobart, Tasmania, Australia

${ }^{8}$ Princess Alexandra Hospital, QLD Health, Woolloongabba, Queensland, Australia

${ }^{9}$ Townsville Hospital, QLD Health, Townsville, Queensland, Australia

${ }^{10}$ Orange and Bathurst Health Services, NSW Health, North Sydney, New South Wales, Australia

${ }^{11}$ Inpatient Rehabilitation, Echuca Regional Health, Echuca, Victoria, Australia

${ }^{12}$ Stroke and Ageing Research, Department of Medicine, School of Clinical Sciences, Monash University, Clayton, Victoria, Australia

${ }^{13}$ Florey Institute of Neuroscience and Mental Health, University of Melbourne, Melbourne, Victoria, Australia

${ }^{14}$ Department of Neuroscience, Central Clinical School, Monash University,

Melbourne, Victoria, Australia

${ }^{15}$ Occupational Therapy Department, Alfred Hospital, Melbourne, Victoria, Australia

Twitter Hoang Phan @thiphan8 and Natasha A Lannin @A-4195-2013

Contributors HC, MD, GMP, SG, KFo, KFr and DAC contributed to study design and concept. JK and DAC contributed to statistical analyses. HP, HC, LW, RW, FR and LA participated in manuscript preparation, editing and revision, and agreed on the final version of the paper. NAL contributed to interpretation of results and was heavily involved in the final preparation of the paper.

Funding The AuSCR was supported by grants from the NHMRC (1034415), Monash University, Queensland Health, Stroke Foundation, Allergan, Ipsen and Boehringer Ingelheim.

Competing interests DAC is the data custodian for the Australian Stroke Clinical Registry and is supported by a National Health and Medical Research Council fellowship (1154273). She has received grants paid to her institution from Stroke Foundation, Melbourne Health, Victorian Government, Queensland Government, Tasmanian Government, South Australian Government, Western Australian Government, Boehringer Ingelheim, Medtronic, Pfizer, Amgen and Shire. NAL is the Chair of the Management Committee of the Australian Stroke Clinical Registry and a member of the Stroke Foundation Clinical Council; NAL is supported by a Heart Foundation fellowship (102055).

Patient consent for publication Not required.

Ethics approval All participating hospitals have provided ethical and governance approvals for AuSCR data collection and analysis. Ethical approval was obtained from the AlHW to conduct data linkage to the NDI and from the Tasmanian Human Research Ethics Committee to conduct this data analysis (reference H0017787).

Provenance and peer review Not commissioned; externally peer reviewed.

Data availability statement Data are available upon reasonable request. Data may be obtained from a third party and are not publicly available. Contact can be made with the corresponding author for queries relating to unpublished data.

Supplemental material This content has been supplied by the author(s). It has not been vetted by BMJ Publishing Group Limited (BMJ) and may not have been peer-reviewed. Any opinions or recommendations discussed are solely those of the author(s) and are not endorsed by BMJ. BMJ disclaims all liability and responsibility arising from any reliance placed on the content. Where the content includes any translated material, BMJ does not warrant the accuracy and reliability of the translations (including but not limited to local regulations, clinical guidelines, terminology, drug names and drug dosages), and is not responsible for any error and/or omissions arising from translation and adaptation or otherwise.

Open access This is an open access article distributed in accordance with the Creative Commons Attribution Non Commercial (CC BY-NC 4.0) license, which permits others to distribute, remix, adapt, build upon this work non-commercially, and license their derivative works on different terms, provided the original work is properly cited, appropriate credit is given, any changes made indicated, and the use is non-commercial. See: http://creativecommons.org/licenses/by-nc/4.0/.

\section{ORCID iDs}

Mitchell Dwyer http://orcid.org/0000-0002-9956-2569

Gregory M Peterson http://orcid.org/0000-0002-6764-3882

Hoang Phan http://orcid.org/0000-0003-0506-2924

Dominique A Cadilhac http://orcid.org/0000-0001-8162-682X

Natasha A Lannin http://orcid.org/0000-0002-2066-8345

\section{REFERENCES}

1 Dwyer M, Rehman S, Ottavi T, et al. Urban-rural differences in the care and outcomes of acute stroke patients: systematic review. J Neurol Sci 2019;397:63-74.

2 Fleet R, Bussières S, Tounkara FK, et al. Rural versus urban academic hospital mortality following stroke in Canada. PLoS One 2018;13:e0191151.

3 Harnod D, Choi W-M, Chang R-E, et al. Are major medical centers better for stroke and myocardial infarction patients in Taiwan? A nationwide population-based study. Int J Gerontol 2010;4:137-42.

4 Lichtman JH, Leifheit-Limson EC, Jones SB, et al. 30-day riskstandardized mortality and readmission rates after ischemic stroke in critical access hospitals. Stroke 2012;43:2741-7.

5 Borhani-Haghighi A, Safari R, Heydari ST, et al. Hospital mortality associated with stroke in southern Iran. Iran J Med Sci 2013;38:314.

6 Hemphill JC, Newman J, Zhao S, et al. Hospital usage of early donot-resuscitate orders and outcome after intracerebral hemorrhage. Stroke 2004;35:1130-4.

7 Ido MS, Bayakly R, Frankel M, et al. Administrative data linkage to evaluate a quality improvement program in acute stroke care, Georgia, 2006-2009. Prev Chronic Dis 2015;12:E05.

8 Kilkenny MF, Dewey HM, Sundararajan V, et al. Readmissions after stroke: linked data from the Australian stroke clinical registry and hospital databases. Med J Aust 2015;203:102-6.

9 Saposnik G, Baibergenova A, O'Donnell M, et al. Hospital volume and stroke outcome: does it matter? Neurology 2007;69:1142-51.

10 Thompson MP, Zhao X, Bekelis K, et al. Regional variation in 30-day ischemic stroke outcomes for Medicare beneficiaries treated in get with the Guidelines-Stroke hospitals. Circulation 2017;10.

11 Santos N, Tavares D, Dias F. Quality of life comparasion of elderly urban and rural stroke victims. Revista de Pesquisa: Cuidado é Fundamental Online 2014;6:387-97.

12 Nuttaset Manimmanakorn M, Vichiansiri R, Nuntharuksa C. Quality of life after stroke rehabilitation among urban vs. rural patients in Thailand. J Med Assoc Thai 2008;9:394-9.

13 Cadilhac DA, Lannin NA, Anderson CS, et al. Protocol and pilot data for establishing the Australian stroke clinical Registry. Int J Stroke 2010;5:217-26.

14 Cadilhac DA, Kilkenny MF, Levi CR, et al. Risk-adjusted hospital mortality rates for stroke: evidence from the Australian stroke clinical Registry (AuSCR). Med J Aust 2017;206:345-50.

15 National Stroke Foundation. National stroke audit: acute services report 2015, 2015. Available: https://informme.org.au/en/stroke-data/ Acute-audits

16 Dillman DA. The design and administration of mail surveys. Annu Rev Sociol 1991;17:225-49.

17 Lannin NA, Anderson C, Lim J, et al. Telephone follow-up was more expensive but more efficient than postal in a national stroke Registry. J Clin Epidemiol 2013;66:896-902.

18 EuroQol Group. EuroQol-a new facility for the measurement of health-related quality of life. Health Policy 1990;16:199-208.

19 Australian Bureau of Statistics. Australian standard geographical classification (ASGC),, 2011. Available: http://www.abs.gov.au/ AUSSTATS/abs@.nsf/allprimarymainfeatures/8B8ABC8EC62D8F46 CA2570AE000DD3B5?opendocument

20 Statistics ABo. ABS Maps, 2020. Available: https://itt.abs.gov.au/itt/r. jsp?ABSMaps

21 Counsell C, Dennis M, McDowall M, et al. Predicting outcome after acute and subacute stroke. Stroke 2002;33:1041-7.

22 Australian Bureau of Statistics. Socio-Economic indexes for areas (SEIFA), 2018. Available: https://www.abs.gov.au/AUSSTATS/abs@. nsf/Lookup/2033.0.55.001Main+Features12016? OpenDocument 
23 StataCorp L. Stata data analysis and statistical software (special edition release) 2007;10:733.

24 Stroke Foundation. Clinical guidelines for stroke management, 2020. Available: https://informme.org.au/en/Guidelines/Clinical-Guidelinesfor-Stroke-Management

25 Stroke Foundation. Acute stroke services framework, 2019. Available: https://strokefoundation.org.au/-/media/E6682A70FFF0 489FA66D28042C0FF472.ashx?la=en

26 Dwyer M. Health care providers' perceptions of factors that influence the provision of acute stroke care in urban and rural settings: a qualitative study [thesis chapter]. Regional differences in acute stroke care and patient outcomes. Hobart, Australia: University of Tasmania, 2020.

27 Cadilhac DA, Purvis T, Kilkenny MF, et al. Evaluation of rural stroke services: does implementation of coordinators and pathways improve care in rural hospitals? Stroke 2013;44:2848-53.

28 Stroke Foundation. National stroke audit acute services report, 2017. Available: https://informme.org.au/en/stroke-data/Acuteaudits

29 National Stroke Foundation. Clinical audit: organisational survey report 2013, 2013. Available: https://informme.org.au/-/media/E427 FAC31B934527BDA5F35CC7DEB699.ashx?la=en

30 Stroke Unit Trialists' Collaboration. Organised inpatient (stroke unit) care for stroke. Cochrane Database Syst Rev 2013;11:CD000197.

31 Stroke Foundation. National stroke audit: acute services report 2019, 2019. Available: https://informme.org.au/-/media/ODAA2643E8F7 424C84D384EB16CF0716.ashx?la=en

32 Australian Stroke Clinical Registry (AuSCR). Annual report, 2018. Available: https://auscr2.files.wordpress.com/2020/03/auscr-2018annual-report-final.pdf

33 Baatiema L, Otim ME, Mnatzaganian G, et al. Health professionals views on the barriers and enablers to evidence-based practice for acute stroke care: a systematic review. Implement Sci 2017;12:74.

34 Kapral MK, Hall R, Gozdyra P, et al. Geographic access to stroke care services in rural communities in Ontario, Canada. Can J Neurol Sci 2020;47:301-8.

35 Moloczij N, Mosley I, Moss KM, et al. Is telemedicine helping or hindering the delivery of stroke thrombolysis in rural areas? A qualitative analysis. Intern Med J 2015;45:957-64.
36 Joubert J, Prentice LF, Moulin T, et al. Stroke in rural areas and small communities. Stroke 2008;39:1920-8.

37 Bladin CF, Kim J, Bagot KL, et al. Improving acute stroke care in regional hospitals: clinical evaluation of the Victorian stroke telemedicine program. Med J Aust 2020;212:371-7.

38 Lindley RI. Telemedicine is improving outcomes for patients with stroke. Med J Aust 2020;212:364-5.

39 Koifman J, Hall R, Li S, et al. The association between rural residence and stroke care and outcomes. J Neurol Sci 2016;363:16-20.

40 Dalli LL, Kim J, Thrift AG, et al. Disparities in antihypertensive prescribing after stroke. Stroke 2019;50:3592-9.

41 Australian Institute of Health and Welfare. A snapshot of men's health in regional and remote Australia. Australian Institue of Health and Welfare, 2010.

42 Australian Institute of Health and Welfare. Australia's health 2012. Australian Institute of Health and Welfare, 2012.

43 Pateman KA, Cockburn NL, Batstone MD, et al. Quality of life of head and neck cancer patients in urban and regional areas: an Australian perspective. Aust J Rural Health 2018;26:157-64.

44 Emery JD, Walter FM, Gray V, et al. Diagnosing cancer in the bush: a mixed-methods study of symptom appraisal and help-seeking behaviour in people with cancer from rural Western Australia. Fam Pract 2013;30:294-301.

45 Kilkenny MF, Lannin NA, Anderson CS, et al. Quality of life is poorer for patients with stroke who require an interpreter. Stroke 2018;49:761-4.

46 Thayabaranathan T, Andrew NE, Kilkenny MF, et al. Factors influencing self-reported anxiety or depression following stroke or TIA using linked registry and hospital data. Qual Life Res 2018;27:3145-55.

$47 \mathrm{Kim}$ H-Y. Statistical notes for clinical researchers: effect size. Restor Dent Endod 2015;40:328-31.

48 Schwamm L, Reeves MJ, Frankel M. Designing a sustainable national Registry for stroke quality improvement. Am J Prev Med 2006;31:S251-7.

49 Australian Institute of Health and Welfare. Admitted patient care 2017-18: Australian hospital statistics, 2019. Available: https:// www.aihw.gov.au/reports/hospitals/admitted-patient-care-2017-18/ contents/at-a-glance 